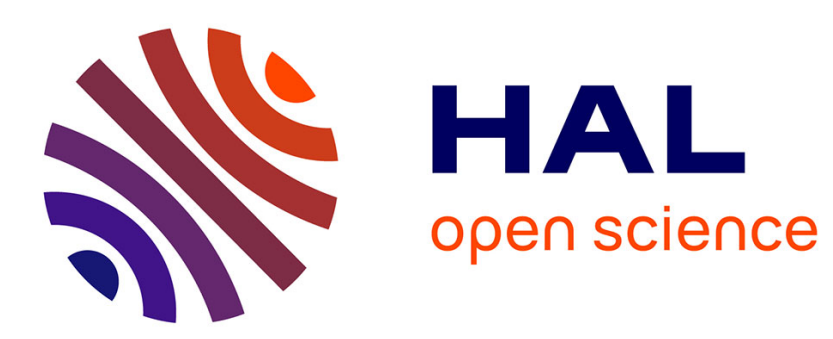

\title{
GRAIN BOUNDARY DIFFUSION OF Co AND Ni IN BICRYSTALLINE AND POLYCRYSTALLINE NiO
}

\author{
Franck Barbier, M. Déchamps
}

\section{To cite this version:}

Franck Barbier, M. Déchamps. GRAIN BOUNDARY DIFFUSION OF Co AND Ni IN BICRYSTALLINE AND POLYCRYSTALLINE NiO. Journal de Physique Colloques, 1988, 49 (C5), pp.C5575-C5-580. 10.1051/jphyscol:1988571 . jpa-00228068

\section{HAL Id: jpa-00228068 https://hal.science/jpa-00228068}

Submitted on 1 Jan 1988

HAL is a multi-disciplinary open access archive for the deposit and dissemination of scientific research documents, whether they are published or not. The documents may come from teaching and research institutions in France or abroad, or from public or private research centers.
L'archive ouverte pluridisciplinaire HAL, est destinée au dépôt et à la diffusion de documents scientifiques de niveau recherche, publiés ou non, émanant des établissements d'enseignement et de recherche français ou étrangers, des laboratoires publics ou privés. 
GRAIN BOUNDARY DIFFUSION OF CO AND Ni IN BICRYSTALLINE AND POLYCRYSTALLINE NiO

\author{
F. BARBIER and M. DECHAMPS
}

Laboratoire de Chimie des Solides, CNRS-UA 446, Bât. 414, Université Paris-Sud, F-91405 orsay Cedex, France

\begin{abstract}
Résumé - La diffusion intergranulaire de Co et de $\mathrm{Ni}$ a été étudiée dans des bicristaux de NiO de flexion symétrique d'axe $\langle 001\rangle$ et $\langle 011\rangle$. Aucune diffusion préférentielle le long des joints n'a été mise en évidence. Il est vraisemblable que la diffusion intergranulaire des cations est au plus égal à $10^{3} \mathrm{D}$, et non de l'ordre de $10^{5} \mathrm{D}$ comme il a été publié. En outre, il est peu probable que les impuretés soient entièrement responsables des divergences observées.
\end{abstract}

\begin{abstract}
Grain boundary diffusion of Co and Ni has been studied in $\langle 001\rangle$ and $\langle 011\rangle$ symmetrical tilt NiO bicrystals. No preferential intergranular diffusion has been detected. It is thought that cation diffusion along grain boundaries is less than $10^{3} \mathrm{D}$, where $D$ is the lattice diffusion coefficient, and not of the order of $10^{5} \mathrm{D}$ as published. Moreover, it is unlikely that impurities are entirely responsible for the discrepancies.
\end{abstract}

\title{
1. INTRODUCTION
}

It is known that diffusion in materials proceeds more rapidly along grain boundaries than through the lattice. In metallic systems, grain boundary diffusion has been studied extensively and reviewed in several papers $/ 1,2 /$. In oxides, diffusion along grain boundaries has also been investigated, but to a much lesser extend /3-5/. However, a number of results have been recently published on nickel oxide. With regard to cation diffusion, Chen and Peterson $/ 6 /$ found an enhanced diffusion of Co and $\mathrm{Cr}$ along grain boundaries in large grained NiO polycrystals grown from the melt, and Atkinson and Taylor /7-9/ have measured the diffusion of $\mathrm{Ni}, \mathrm{Co}, \mathrm{Cr}$ and $\mathrm{Ce}$ along grain boundaries, in fine grained polycrystalline NiO films obtained by oxidation of nickel. Their results concerning Co and $C r$ diffusion are not in good agreement with those of Chen and Peterson, and the origin of the discrepancy was not clarified. Grain boundary diffusion of $\mathrm{Ni}$ in NiO scales containing cerium /10/ or yttrium /11/ was also studied. Data are also available for diffusion of $O$ along $N i O$ grain boundaries $/ 12 /$.

Up to now, all the experiments were performed on polycrystalline Nio, and no attempt was made to find the correlation which might exist between the grain boundary structure and the grain boundary diffusivity. In order to show such a possible relationship, diffusion experiments of $\mathrm{Co}$ and $\mathrm{Ni}$ have been carried out on well defined $\langle 001\rangle$ and $\langle 011\rangle$ symmetrical tilt $\mathrm{NiO}$ grain boundaries.

\section{EXPERIMENTAL STUDY OF GRAIN BOUNDARY DIFFUSION IN NIO BICRYSTALS}

Nickel oxide bicrystals with $\langle 001\rangle$ and $\langle 011\rangle$ symmetrical tilt grain boundaries were grown from the melt by the flame fusion technique 
/13/, from high purity NiO powder (99.999). Bicrystalline lamellae, $2 \mathrm{~mm}$ thick, were first annealed $\left(1600^{\circ} \mathrm{C}, 30 \mathrm{~h}\right)$ to relieve stresses before being polished.

A second equilibrium anneal was carried out, at an oxygen partial pressure $\left(\mathrm{PO}_{2}\right)$ and a temperature $(\mathrm{T})$ identical to those used for the subsequent diffusion anneal, in order to obtain an equilibrium defect structure, i.e. an uniform point defect distribution. The bicrystals were annealed for twice as long as the time considered for the subsequent diffusion anneal.

The tracers, $\mathrm{Co}$ and $\mathrm{Ni}$, were deposited on the surface normal to the boundary. The co tracer was deposited by radiofrequency sputtering of CoO. The ${ }^{3} \mathrm{Ni}$ tracer was applied to the surface by evaporation of radioactive $\mathrm{NiCl}_{2}$.

Diffusion anneals were carried out in the temperature range $600-1200^{\circ} \mathrm{C}$ at $\mathrm{PO}_{2}=0.2$ atm and $\mathrm{PO}_{2}=1$ atm. The diffusion time ( $t$ ) was chosen to get diffusion profiles (Fig. 1) well suited for the analysis technique which was used (for example, $\beta>10$ and $\Phi>10^{\circ}$ in the case of an electron microprobe analysis). In this study, diffusion parameters ( $T$, $t$ ) were fixed in order to discriminate easily grain boundary diffusion relative to lattice diffusion, basing upon the published lattice and grain boundary diffusion coefficients (Fig. 2).

Co diffusion in bicrystals was studied quantitatively by electron microprobe analysis. The local concentration of Co in the ox-Oy plane (Fig. 1) was determined in order to establish isoconcentration profiles in the vicinity of the grain boundary. The limit of detection of Co is 250 to $300 \mathrm{p} \cdot \mathrm{p} . \mathrm{m}$. and the lateral resolution in the Ox-Oy plane is 1 to $2 \mu \mathrm{m}$. The qualitative distribution of ${ }^{6}{ }^{3} \mathrm{Ni}$ tracer in the specimen was observed by autoradiography using Kodak AR10 stripping film.

\section{EXPERIMENTAL RESULTS}

\subsection{Diffusion of cobalt}

Diffusion experiments revealed lattice diffusion coefficients in good agreement with those of Tabet et al. /15/ which were obtained in Nio single crystals, using the same experimental procedure. On the other hand, no preferential grain boundary diffusion was detected in the bicrystals despite a systematic exploration of severals parameters: 1 - Grain boundaries of various misorientation angles ( $\theta$ ) have been studied $\left(10^{\circ}\left\langle\theta_{\langle 00}\right\rangle\left\langle 28^{\circ}\right.\right.$ and $40^{\circ}\left\langle\theta_{\langle 011}\right\rangle\left\langle 160^{\circ}\right) ; 2$ - Taking into account the diffusivity $\alpha D^{\prime} \delta$ published by Chen and Peterson $/ 6 /$ and Atkinson and Taylor $/ 8 /$, a large range of values for $t$ and $T$ was tested to cover an important interval of $\beta$ values; 3 - The point defect concentration was also modified by annealing under low oxygen partial pressure $\left(\mathrm{PO}_{2}=6.10^{-6} \mathrm{~atm}\right)$, or by doping NiO with chromium (Cr $\left.{ }^{3+}\right)$ or yttrium $\left(\mathrm{Y}^{3}+\right)$ ions. In the latter case, it was thought that dopings could have an important extrinsic effect on intergranular diffusion : $\mathrm{Cr}^{3+}$ increases bulk diffusion $/ 15 /$ and segregates at grain boundary $/ 16 /$, and $\mathrm{Y}^{3+}$ influences the oxidation of nickel/17/. All these attempts were unfruitful in revealing excess diffusion along grain boundaries, i.e. the isoconcentration profiles were "flat" whatever the experimental parameters were.

\subsection{Diffusion of nickel}

Grain boundaries of various misorientations have been studied. No preferential diffusion along any grain boundary was detectable on autoradiographs despite using exposure times up to twelve days. 
Fig. 1
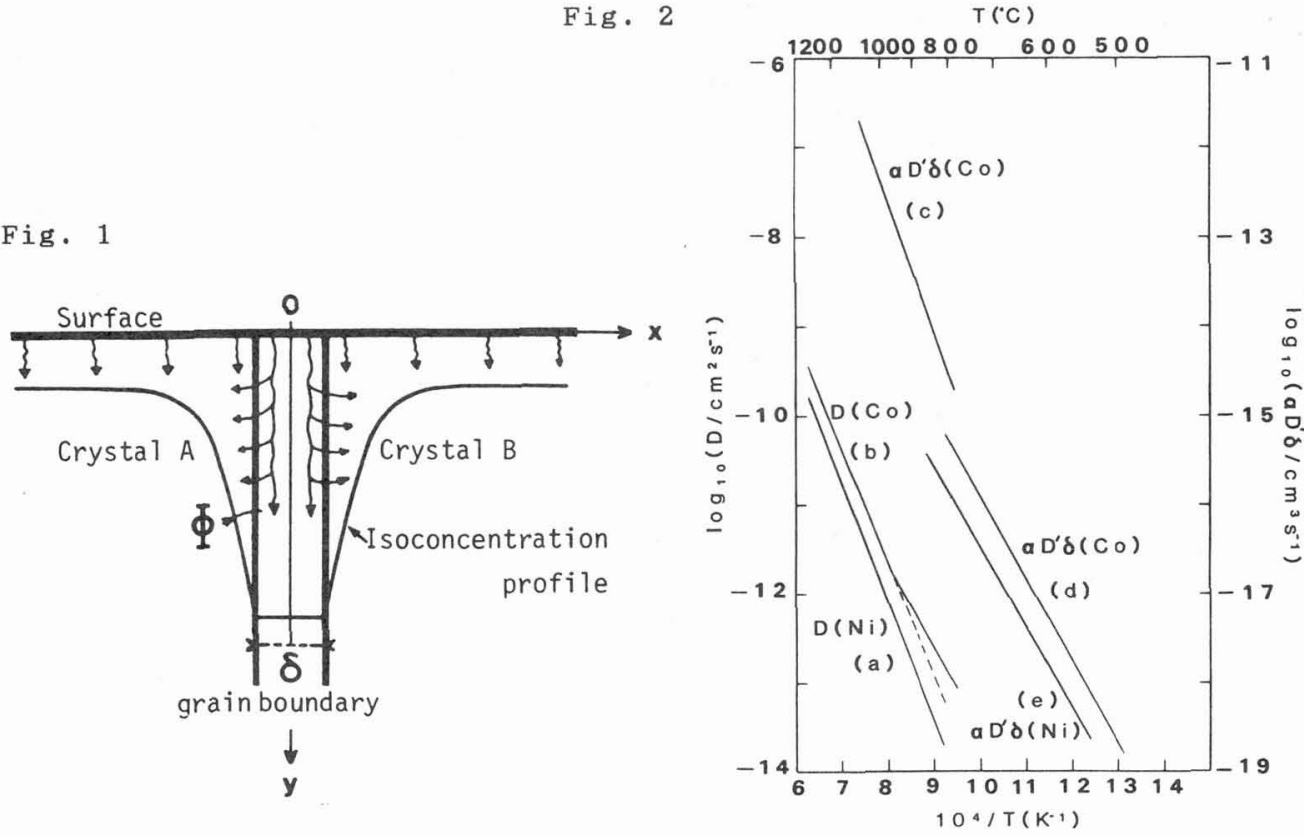

Fig. 1 - Diffusion model in a bicrystal. The grain boundary is represented by a slab of width $\delta$. The shape of the isoconcentration profile is defined by $B=\alpha D^{\prime} \delta / 2 D \sqrt{D E}$ ( $D^{\prime}$ : grain boundary diffusion coefficient; $D$ : lattice diffusion coefficient ; $\alpha$ : segregation factor; $\Phi$ : contour angle).

Fig. 2 - Lattice and grain boundary diffusion coefficients for Co and $\mathrm{Ni}$ in NiO. Curve (a) is from $/ 14 /$, (b) from $/ 15 /$, (c) from $/ 6 /$, (d) from $/ 8 /$ and (e) from $/ 7 /$.

At first sight, this study seems to show that Co and $\mathrm{Ni}$ transport appears the same in the bulk and along the grain boundaries in Nio bicrystals. The result is the same whatever the cristallographic characteristics of the bicrystals are. More precisely, the absence of enhanced intergranular diffusion under these experimental conditions means that grain boundary diffusion coefficients of cobalt and nickel are several orders of magnitude lesser than those published earlier.

\section{DISCUSSION}

Our diffusion experiments in bicrystals have not revealed any obvious preferential diffusion of cobalt or nickel along grain boundaries. This conclusion is in complete disagreement with the results published by different authors. Indeed, Chen and Peterson /6/ and Atkinson and Taylor /7,8/ have determined grain boundary diffusion coefficients several times greater than lattice diffusion coefficients ( ${ }^{\prime} / D \approx 10^{5}$ assuming $\delta \approx 1 \mathrm{~nm}$ and $\alpha \approx 1$ ). The origin of such contradictory results may be due either to the experimental procedure or to the characteristics of the materials (e.g. impurities or microstructure).

\subsection{Influence of the experimental procedure}

We have to examine whether the diffusion conditions (temperature and time) and the analysis techniques used in the study are well suited to detect grain boundary diffusion. As an example, Fig. 3 shows 
simulated isoconcentration profiles expected after diffusion of cobalt at $800^{\circ} \mathrm{C}$ for 100 hours using the Suzuoka's solution and Atkinson and Taylor's data. The following points must be noted : 1 - when Co detection limit $(0.03 \%)$ is reached in the bulk, grain boundary concentration $(\approx 1 \%)$ is sufficiently high for co to be detected easily by microprobe ; 2 - The diameter of the probe $(\approx 1 \mu \mathrm{m})$ and the angle $\Phi$ of the isoconcentration profiles are compatible with a local analysis in the vicinity of the grain boundary for intergranular diffusion to be detected. Simulated profiles using chen and Peterson'data lead to the same conclusions as shown elsewhere /18/.

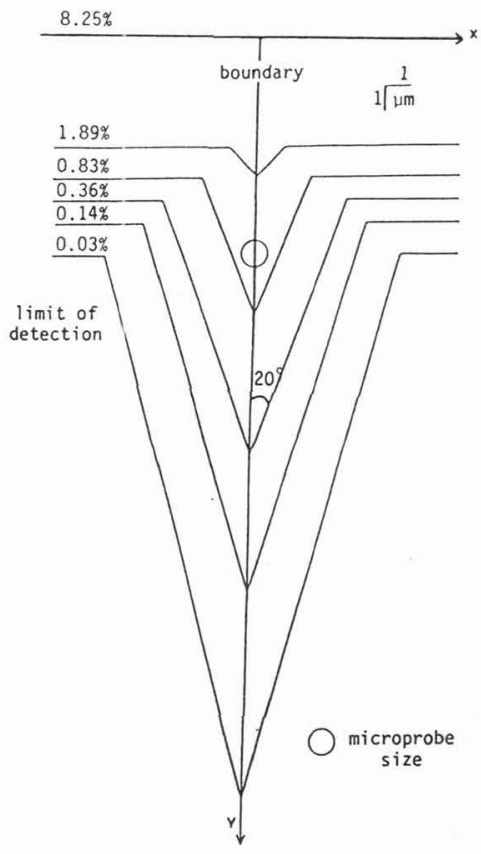

Fig. 3

Simulated isoconcentration profiles from Atkinson and Taylor's data after diffusion of Co at $800^{\circ} \mathrm{C}$ for $100 \mathrm{~h} \quad\left(\alpha D^{\prime} \delta=4.810^{-16} \mathrm{~cm}^{3} \mathrm{~s}^{-1}\right.$, B $\approx 10$ ).

Thence, as our results have shown that the behaviour of the bicrystals is representative with regard to the diffusion in the bulk, it is expected that an enhanced diffusion along grain boundaries would be observed if the published data were valid. Consequently, the nonobservation of preferential diffusion of Co in our bicrystals means that $D^{\prime} / D$ is less than $10^{5}$. It is possible to get an insight on the actual value of $D^{\prime}$ by simulating isoconcentration profiles for different values of $\alpha D^{\prime} / D$. It was concluded that any grain boundary diffusion corresponding to $\alpha \mathrm{D}$ ! /D $>10^{3}$ should have been detected unambiguously by microprobe analysis. Thus, assuming $\alpha \approx 1, D^{\prime}$ is less than $10^{3} \mathrm{D}$, and not of the order of $10^{5} \mathrm{D}$, as published. This conclusion should be also valid for the grain boundary diffusion coefficient of nickel because the physical and chemical properties of $\mathrm{Ni}$ and Co are very similar, and it is also expected that this similarity extends to intergranular properties.

\subsection{Influence of impurities}

Grain boundary diffusion can be influenced by impurities. Therefore, comparison between various results has sense only if grain boundary chemical characteristics are comparable. Ten bicrystals have been analysed in the bulk and at the grain boundaries/18/. Not any 
intergranular precipitation or segregation of impurities was detected. Thence, it appears that diffusion experiments have been carried out on "clean" grain boundaries, free of large amount of impurities.

It has to be noted that our results disagree with those of Atkinson et al $/ 19 /$ concerning two bicrystals furnished to them by us. These authors found considerable contamination of the boundaries and reported that intergranular diffusion was dominated by impurities. In our opinion, the observations mentioned by the authors cannot reflect the real composition of the boundaries, and their conclusions have to be regarded with caution as discussed in another work /18/.

\subsection{Influence of the specimen preparation}

Studies of grain boundary diffusion have been carried out on Nio specimen prepared by different ways. Some of them were obtained by growth from the melt (present work, Chen and Peterson /6/), others by thermal oxidation of nickel foils (Atkinson and Taylor /7,8/, Moosa et al. $(11 /)$. Thus, great attention was paid to the eventual influence of the specimen preparation on diffusion experiments.

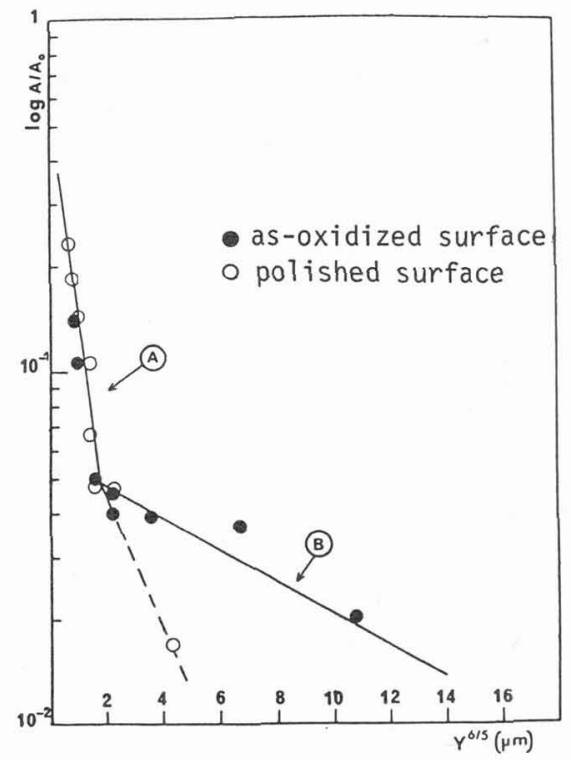

Fig. 4

Diffusion profiles of $63 \mathrm{Ni}$ in polycrystalline $\mathrm{NiO}$ prepared by thermal oxidation. Profiles have been determined after diffusion from an as-oxidized surface and a polished surface by sectioning and counting the tracer activity as detailed in ref. $/ 18,20 /$.

With regard to oxide scales obtained by oxidation of metal, earlier experiments $/ 18,20 /$ revealed that the diffusion results were dramatically dependent upon the procedure used to prepare the specimen surface. To illustrate this point, Fig.4 shows diffusion profiles of ${ }^{3} \mathrm{Ni}$ obtained from an as-oxidized surface and from a polished surface. The results relative to the as-oxidized surface indicate two regions $A$ and $B$ and, at first sight, region $B$ seems to be due to grain boundary diffusion. Reversely, on the polished surface, only one region (A) is revealed, and there is no detectable intergranular diffusion. Such different behaviour is confirmed by autoradiographs. Further experiments have shown that the apparent grain boundary diffusion detected on the as-oxidized surface results of artefacts due to the surface topography of the scale. In fact, grain boundaries are found to be deeply embedded into the Nio scale : deep and narrow canyons are observed at the apex of the boundaries. These flaws distort seriously diffusion experiments, if not removed. 


\section{CONCLUSION}

No obvious preferential diffusion of Co and $\mathrm{Ni}$ along Nio grain boundaries of various crystallographic characteristics has been detected despite a systematic exploration of several parameters. It is thought that the cation grain boundary diffusion coefficient $D^{\prime}$ is probably less than $10^{3} \mathrm{D}$, and not of the order of $10^{5} \mathrm{D}$, as previously reported.

Several assumptions have been made to explain the discrepancies. With regard to the chemical composition, the influence of impurities must be discarded to explain entirely the contradictory results. The origin of the material is also a key factor. In particular, it was shown that diffusion in Nio polycrystals obtained by thermal oxidation such as those used by Atkinson and Taylor /7,8/ and by Moosa et al /11/ was influenced by the preparation of the sample surface. In our opinion, the disagreements with these authors could be due to the microstructure of the materials which were used. With regard to chen and Peterson's samples $/ 6 /$, we do not have sufficient information to. discuss the results which are, in any case, in disagreement with those of Atkinson and Taylor.

The present work points out clearly a lack of reproductibility between various studies of grain boundary diffusion in NiO. It shows that this phenomenon is still far from being fully understood in oxides. Recent results obtained in $\mathrm{MgO} / 22$, which are not in agreement with previous data $/ 23 /$, support this opinion.

\section{REFERENCES}

1 - G.Martin and B.Peraillon, Grain boundary structure and kinetics, Ed. R.W.Balluffi, A.S.M., Metals Parks, Ohio (1980)239.

2 - N.L.Peterson, Int. Met. Rev. 28(1983)65.

3 - W.D.Kingery, J. Amer. Ceram. Soc. 57(1974)74.

4 - J.Philibert, J. Physique 36(1975)C4-411.

5 - A.Atkinson, Solid State Ionics 12(1984)309.

6 - W.K.Chen and N.L.Peterson, J. Amer. Ceram. Soc. 63(1980)566.

7 - A.Atkinson and R.I.Taylor, Phil. Mag. A43(1981)979.

8 - A.Atkinson and R.I.Taylor, Phil. Mag. A45(1982)583.

9 - A.Atkinson and R.I.Taylor, J. Phys. Chem. Solids 47(1986)315.

10 - A.T.Chadwick and R.I.Taylor, Solid State Ionics 12(1984)343.

11 - A.A.Moosa, S.J.Rothman and L.J.Nowicki, Oxid. of Metals $24(1985) 115$.

12 - A.Atkinson, F.C.W.Pummery and C.Monty, Transport in non stoichiometric compounds, Ed. G.Simkovich and V.S.Stubican, Plenum Press, NewYork (1985) 359 .

13 - G.Dhalenne, A.Revcolevschi and A.Gervais, J. Crystal Growth $44(1978) 297$.

14 - A.Atkinson and R.I.Taylor, Phil. Mag. A39(1979)581.

15 - N.Tabet, C.Dolin and C.Monty, Rev. Int. Temp. Refr. 19(1982)413.

16 - M.R.Notis, B.Bender and D.B.Williams, Advances in Ceramics, Ed. L.M.Levinson, Am. Ceram. Soc., 1(1981)91.

17 - A.A.Moosa and S.J.Rothman, Oxid. of Metals 24(1985)133.

18 - F.Barbier, Thèse d'état, Orsay, France (1986).

19 - A.Atkinson, D.P.Moon, D.Smart and R.I.Taylor, J. Mat. Science $21(1986) 1747$.

20 - F. Barbier, J. Bernardini, F. Moya and M.Déchamps, Ceramic Microstructures'86 Symposium, Berkeley, U.S.A. (1986).

22 - A.Roshko and W.D. Kingery, Communication presented at the $89^{: b}$ Annual Meeting Amer. Ceram. Soc., Pittsburgh, U.S.A. (1987).

23 - J.W. Osenbach and V.S. Stubican, J. Amer. Ceram. Soc. 66(1983)191. 